\title{
DISCURSO DE LA CONCORDIA ${ }^{1}$
}

\author{
ÓSCAR ALZAGA VILLAAMIL \\ Catedrático de Derecho Constitucional \\ Universidad Nacional de Educación a Distancia
}

Mis queridos amigos:

En esta noche en que tan justamente se ha premiado la trayectoria sobresaliente de Jordi Pujol, como brillantemente ha expuesto el glosador de sus méritos, Felipe González, me ha honrado la Junta Directiva de la Fundación Fernando Abril con el ruego de que pronuncie lo que en el ritual de estos premios se viene denominando el discurso de la Concordia. Tan desproporcionado es el honor que con esta invitación se me hace que habiendo mucho de honor, que debo agradecer, aún percibo más la responsabilidad que entraña. Y aunque albergo dudas sobre como conllevar tamaña responsabilidad, ya ven Vds. que he aceptado gustoso hacer un elogio de la concordia.

El elogio quizás en mi condición de modesto Catedrático de Derecho constitucional deba revestir el formato del género literario al que en la Universidad denominamos Laudatio. En este grato trance de pronunciar una "laudatio de la concordia" es obligado hacer referencia a que el concepto político de concordia según sostiene Ortega en su "Ensayo del Imperio romano" se acuñó por Cicerón en plena guerra civil, al escribir sus diálogos sobre "La República", puesto que sostiene que sin la Concordia la colectividad ni es propiamente sociedad ni se puede articular en Estado ${ }^{3}$. Si me permiten Vds. una pequeña dosis de pedantería les apostillaré que mucho me temo que en esta ocasión el gran filósofo de nuestro siglo xx no estaba en lo cierto, porque Cicerón que era mejor divulgador que pensador ${ }^{4}$ se limitó a difundir la idea de armonía que sobre la

1 Palabras pronunciadas en Madrid, el 17 de marzo de 2005 en el acto organizado por la Fundación Fernando Abril para entregar su VII Premio Anual a la Concordia.

2 ORTEGA Y GASSET, José: Ensayo del Imperio Romano, publicado inicialmente en el diario de Buenos Aires La Nación, en el verano de 1940. Citamos por Las Atlántidas y Del Imperio Romano, Ed. Revista de Occidente, Madrid, 1960, p. 87.

3 CICERÓN, Marco Tulio: "La República”, años 54 a 51 a. de J. C., Libro II, Capítulo 42 y Libro III, Capítulo 31.

4 El que las ideas que expone en La República "no son en absoluto nuevas u originales mías" es algo confesado por el propio CICERÓN, en el Libro I, Capítulo 8. 
concordia habían concebido en Grecia los estoicos a la vista de la obra militar y política de un Alejandro Magno que buscaba el entendimiento entre pueblos que hasta entonces se habían desconocido ${ }^{5}$. En efecto, la escuela estoica, configurada por intelectuales siempre prestos a elaborar ideas fuerza útiles a los nuevos dirigentes políticos, forjó el concepto de concordia ${ }^{6}$. Entendida así la concordia como germen de la idea de una feliz convivencia de pueblos diversos, integrantes de una misma unidad política, un mismo Estado ${ }^{7}$.

Por supuesto, desde entonces la idea de la concordia transcurre a lo largo del curso del largo río de la Historia del Pensamiento político, adaptándose al perfil propio de cada meandro. Pero permítaseme que desde mi deformación de jurista traiga a colación que la palabra hace fortuna en nuestra Baja Edad Media para designar un pacto o gran acuerdo político que resolvía un problema especialmente delicado. Tal fue el caso en la Corona de Aragón de la Concordia de Alcañiz, de 1412, entre los Parlamentos de Aragón y Cataluña sobre el modo de designar Rey.

O también de la Concordia de Villafranca, de 1461, suscrita entre la Reina Juana, en nombre de su marido el Rey Juan II y la Junta del Principado de Cataluña. El texto original de esta Concordia está redactado en catalán y me es muy grato leerles en el catalán de la época este bellísimo fragmento del Preámbulo de la misma: «Senyor Molt Alt e Molt Excelent. Inestimable es lo bé procehint del compost orde e repós de la cosa pública; lo qual precipuament está en uniformitat e concordia del cap ab lo cors e membres de aquella. E com per la disparitat e discordancia de aquells inmensurables mals provenen, axi per la unitat, orde e acordat voler, divinals bens augment e multiplicació de poques coses en grans succehixen ${ }^{8}$.

Traslado estas palabras al castellano: "Es inestimable el bien que procede del arreglado orden y quietud de la cosa pública, el cual principalmente radica en la uniformidad y concordia de la cabeza con el cuerpo y miembros de aquélla. Y así como de la disparidad y desacuerdo de aquellos provienen innumerables males, así de la unidad, orden y voluntad acorde, vienen el aumento de los bienes divinos y la multiplicación de las cosas pequeñas en grandes".

En Castilla, en el mismo siglo xv, se dio la Concordia de Segovia, subtitulada "Sobre la gobernación del Reino de Castilla" firmada en esa ciudad el 15 de enero de 1475 , cuyas primeras palabras rezan así: "Por quanto por quitar algunas dubdas que ocurrían o podrían nacer cerca de la forma y orden que se debía tener en la administración e gobernación destos reinos de Castilla e de León, entre Nos la Reina doña Isabel... e el Rey don Fernando, mi señor..." (y

5 Cfr. BARKER, Ernst: From Alexander to Constantine: Pasajes and Documents Illustrating the History of Social and Political Ideas. B.C.-A.D. 337, Oxford, 1956.

6 BRÉHIER, Émile: Chrysippe et l'ancien stoïcisme. Nueva edición revisada, París, 1950.

7 Vid. SABINE, George H.: Historia de la Teoría política; Ed. Fondo de Cultura Económica; 3. ${ }^{a}$ ed. Española, México, 1965. Apartado: "Concordia y Monarquía", pp. 116 a 118.

8 AAVV: Manual de Historia del Derecho Español; Tomo II: "Antología de Fuentes del Antiguo Derecho"; Décima reimpresión, Madrid, 1984, número 1076, p. 903. 
prosigue el texto dispositivo de esta Concordia que sale al paso previsoramente de posibles conflictos de presente y de futuro).

En la Edad Moderna, en el marco de la Monarquía absoluta, sigue habiendo en nuestra Historia del Derecho público Concordias, aunque las mismas se suscriben más bien, en unos casos, entre la Jurisdicción real y la inquisitorial (y así cabe recordar la llamada Concordia Catalana de 1512 o la denominada Concordia de Castilla de 10 de marzo de 1553) y, en otros supuestos, entre las jurisdicciones real y eclesiástica (buen ejemplo, lo constituye por cierto la Concordia Fachenetti, de 1640, que aprueba unas Ordenanzas de la Nunciatura en Madrid).

Ese aprecio por salvar tensiones y desacuerdos con buenas dosis de concordia se sigue pudiendo detectar a lo largo de nuestra Historia, siglo tras siglo, aunque ello no permite obviamente ocultar cuanto hay de confrontación entre posiciones radicales durante nuestro convulso siglo XIX entre las llamadas Dos Españas.

Pero no todo en el siglo XIX fue contienda ayuna de diálogo y carente de entendimientos y compromisos. Así de la fina pluma de Juan Valera emanan en 1864 unos denominados "Estudios críticos sobre literatura, política y costumbres de nuestros días $"{ }^{9}$, modelo de prosa pulcra y serena, puesta al servicio de la exaltación de los valores de la convivencia en libertad y huérfana de todo extremismo. En las palabras de Don Juan Valera se palpa una tradición española, viva aún en plena crisis socio-política de nuestra historia decimonónica, que suele olvidarse en demasía y que debe ser reivindicada. Una tradición que si a veces se nos aparece como crítica y defensiva, quizás porque siempre ha tenido que conquistarse a base de esfuerzo el derecho a existir, porque se ha visto obligada a buscar el aire que respirar, el que tenía que hacer vibrar para hacer sonar en esta dura tierra nuestra unas cuantas palabras mesuradas y justas, unas pocas palabras verdaderas ${ }^{10}$.

A esa tradición alude sin duda el personaje de "La velada en Benicarló" al que Azaña hace decir "Yo hablo de la tradición liberal y humanitaria española, porque esa tradición existe aunque nos la hayan querido ocultar... Ha habido siempre un arroyuelo murmurante de gentes descontentas, del cual arroyuelo nosotros venimos y hemos convertido en ancho río" ${ }^{11}$.

Ciertamente el ancho río torrencial que se desbordó en 1936 no fue resultante de ningún manantial liberal ni de ningún afluente humanista. No hubo lugar para la concordia ni en el estallido de la guerra civil ni en sus amargas consecuencias.

Pero esta Fundación que lleva el nombre de un amigo inolvidable, Fernando Abril, se propone mantener vivo el recuerdo y el orgullo por aquella gesta de recuperación de una larga tradición histórica de convivencia civiliza-

9 VALERA, Juan: Estudios críticos sobre literatura, política y costumbres de nuestros dias. Ed. Imprenta de Álvarez, Madrid, 1864.

10 MARÍAS, Julián: Los Españoles, Ed. Revista de Occidente; Madrid, 1962, p. 127.

11 AZAÑA, Manuel: La velada de Benicarló. Ed. Losada, Buenos Aires, 1939, p. 137. 
da, por aquella magna obra de comprensión recíproca y buen sentido que fue la transición. Nuestra transición a la democracia. Obviamente no se espera que mis palabras se conviertan en lo que denominó un día Marco Aurelio un "testamento de gratitud aguas arriban. Es innecesario. En estos lares hay contraída una deuda impagable con cuantos lideraron, cooperaron y cooperamos, en primer término con la pretransición (etapa en la que se crean las condiciones que harían más tarde posible la transición) y permítaseme citar aquí una palabras del Editorial titulado "razón de ser" con el que Joaquín Ruiz Giménez abrió en octubre de 1963 el n. ${ }^{\circ} 1$ de la Revista Cuadernos para el Diálogo. Decía así: "Sólo tres cualidades se exigen para lograr presencia activa en estas páginas: un mutuo respeto personal, una alerta sensibilidad para todos los valores que dan sentido y nobleza a la vida humana y un común afán de construir un mundo más libre, más solidario y más justo". Para añadir: "La previsión de la dificultad y hasta del riesgo no pueden ser freno, sino aguijón y estímulo, para quienes aceptan serena y esforzadamente esta sugestiva empresa de transformar el silencio resentido, el monólogo narcisista o la polémica hiriente en alta y limpia comprensión de los hechos concretos y de las razones ajenas, y en fecunda invención o ensayo de nuevas fórmulas de convivencia ${ }^{12}$. Y, por supuesto, la deuda de la colectividad existe así mismo para con quienes protagonizaron, en uno u otro papel, la obra política denominada La transición por antonomasia, algo que parecía dotado de una audacia sobresaliente pese a que era sobre todo la asunción honrada y compartida por un anchísimo espectro de las fuerzas políticas del derecho de nuestras gentes a vivir en libertad y justicia en el marco de un moderno Estado de Derecho en el seno de la Europa de nuestro tiempo. Pero la determinación y buen criterio con que se hizo la transición no deja de ser un monumento magistral al sentido de la concordia entre todos los españoles y pueblos de España que bien merece este recuerdo anual.

Pero la concordia no es una virtud cívica que sólo deba cultivarse en los momentos más graves de la Historia, sino que requiere una práctica cotidiana. Concibamos la concordia como una planta de hoja perenne. Y a la par más como una actitud dinámica que estática. La concordia conlleva el esfuerzo de superar el impulso de los extremismos, que conduce hacia el radicalismo en espiral y a enfrentamientos cada vez más crispados y de resultados imprevisibles y, en todo caso, inquietantes. La práctica de la concordia es sustituir tal impuso hacia el choque, hacia la confrontación incluso violenta, por un impulso alternativo de moderación, convergencia y búsqueda de posiciones de encuentro. Pensarán Vds. que mi subconsciente centrista emerge. Pero no hablo de política stricto sensu, sino de valores de la mejor civilización occidental que nadie puede olvidar un solo momento y que ninguno de nosotros deseamos que puedan peligrar.

En efecto, si tomamos en nuestras manos el opúsculo de Francesc Cambó Por la Concordia, vemos que, en octubre de 1927, escribe en su introducción

12 Cuadernos para el Diálogo, núm. 1, año 1963, Editorial Razón de ser pp. 1 y 2. 
literalmente: «En el mes de enero de 1923 di en la Asociación catalanista de la Barceloneta una Conferencia que revistió caracteres de testamento político.

Había llegado yo entonces — sigue afirmando Cambó- a la conclusión de que las resistencias y prevenciones de Madrid y las inquietudes e impaciencias de Barcelona quitaban por mucho tiempo toda eficacia a mi acción de tantos años, encaminada a buscar una solución española, de efusiva concordia, al problema de Cataluña" ${ }^{13}$.

La concordia de que escribía el procer catalán la adjetivaba de efusiva con buen criterio, porque esa nota de afecto generoso es la que distingue la mejor convivencia de la mera coexistencia.

Es cierto que la moderna politología se define a sí misma como una teoría del conflicto. Si se quiere puede incluso denominarse como una teoría de las borrascas, de los vendavales y de las tormentas. Es decir, una Sturmlehre, como dijera Jacobo Burckhardt ${ }^{14}$. Y mucho hay de verdad en ello porque las sociedades sin conflictos no son utópicas; son imposibles.

Ahora bien, los que creemos que la democracia se asienta en el principio del pluralismo político, reconocemos la obvia existencia de tesis y posiciones divergentes y aun contrapuestas en la arena política. Pero para nosotros sus sostenedores son adversarios en forma más o menos coyuntural o permanente, pero no enemigos. El concepto de enemigo ya en Roma implicaba una relación de hostilidad y la misma presuponía la guerra. En el célebre trabajo que suscribió en 1938 Carl Schmitt, a la postre sólo entiende que haya en política amigos y enemigos y simplemente el enemigo es — para él— el "no amigo" frente al cual hay una contraposición de hostilidad psíquica, moral, económica, propagandística, que obliga a su destrucción por todas las vías, pues es preciso hacerle lo que llamó "la guerra total" ${ }^{15}$. Esta visión sirvió, como sabemos, de alimento ideológico al totalitarismo más cruento y horrendo.

Ciertamente cabe otra visión de la relación en una sociedad pluralista entre quienes tienen intereses o concepciones diferentes, que pasa por el respeto recíproco de sus personas e ideas, aunque no se compartan.

La comunidad que asume el reto de vivir en democracia, en el marco de los principios y valores propios de la Constitución, tolera las discrepancias aunque ha de ser intolerante con la violencia y el terrorismo porque no puede la tolerancia ser tolerante con la intolerancia violenta sin asfixiar a la propia tolerancia. Y opta por trascender todos los antagonismos y tensiones existentes político-partidistas, económico sociales o de otro tipo en un orden jurídico

13 CAMBÓ, Francesc: Per la concordia, Ed. LLiberia Catalonia, Barcelona, 1927, p. 7. Para la versión castellana vease: Por la concordia, Ed. Alianza Editorial / Enciclopedia Catalana, Madrid, 1986, p. 9.

14 BURCKHARDT, Jacobo. Cfr. ALZAGA VILLAAMIL, Óscar: «En torno a un posible nuevo enfoque de la asignatura denominada Derecho político", en Revista de Derecho Político, núm. 4, año 1979 , p. 19

15 SCHMITT, Carl: El concepto de lo político ("Corolario 2: Sobre la relación existente entre los conceptos de guerra y enemigon), Berlín, 1938. Citamos por la traducción española; Ed. Folios, Buenos Aires, 1984, pp. 99 a 108. 
que institucionaliza la primacía de los derechos y libertades fundamentales de los ciudadanos y que se encuentra regido por los órganos y reglas de funcionamiento propios de un Estado de Derecho. Y todo ello desde un status de ciudadanía compartida con afectuosa concordia, que dijera Cambó; porque concordia etimológicamente significa, de un lado, unión de los corazones ("cum corde") y, de otro, tiene el sentido de armonía musical de sonidos ("cum cordis"), lo que evoca que la opinión pública puede conformarse no por la vía tosca de la greña, sino situando con buen "seny" las diversas opiniones como notas de un pentagrama, de forma que los sonidos configuren una grata melodía, dotada de armonía.

Queridos amigos, nada más. Sólo me resta invitarles a alzar su copa y brindar porque entre todos siempre prevalezca la práctica de la virtud de la concordia. 